\title{
Promoting Teacher Professional Development: the Role of Individual and Contextual Factors
}

\author{
Zahra Rastegar Haghighi Shirazi (Corresponding author) \\ Department of English Language Teaching, Shiraz Branch, Islamic Azad University, Shiraz, Iran \\ E-mail: zrastegar@gmail.com \\ Mohammad Sadegh Bagheri \\ Department of English Language Teaching, Shiraz Branch, Islamic Azad University, Shiraz, Iran \\ Firooz Sadighi \\ Department of English Language Teaching, Shiraz Branch, Islamic Azad University, Shiraz, Iran \\ Lotfollah Yarmohammadi \\ Department of English Language Teaching, Shiraz Branch, Islamic Azad University, Shiraz, Iran
}

Received: 19-07-2014

doi:10.7575/aiac.ijalel.v.4n.1p.41
Accepted: 21-08-2014

Published: 01-01-2015

URL: http://dx.doi.org/10.7575/aiac.ijalel.v.4n.1p.41

\begin{abstract}
The purpose of this study was to investigate the individual and contextual factors conducive to teacher professional development. The study which aimed at identifying the predictors of teacher development consisted of in-depth interviews with 15 teachers. Data gleaned from in-depth interviews were analyzed utilizing content analysis. Some common themes that emerged from the qualitative data included (a) learning goal orientation (b) teacher self-efficacy, (c) professional commitment (d) organizational climate, and (e) learning organization culture. Theoretical and practical implications of the study are discussed.
\end{abstract}

Keywords: Teacher professional development, Learning goal orientation, Teacher self-efficacy, Professional commitment, Organizational climate, Learning organization culture

\section{Introduction}

Educational system worldwide is changing swiftly. Policy makers and practitioners today have become well cognizant of the paramount role of teachers as professionals in enhancing academic excellence and improving student achievements and they have urged teachers to accelerate gains in student achievements. They have understood that "Regulations cannot transform schools; only teachers, in collaboration with parents and administrators, can do that" (Darling-Hammond,1996, p. 228). Similarly, the multifarious changes happening to societal and global needs nowadays, in addition to revolutionization of student dynamic has brought teachers to the fore. As Garet, Porter, Desimone, Birman, and Yoon (2001) insist "Teachers are necessarily at the center of reform, for they must carry out the demands of high standards in the classroom" (p. 916). Teachers, too, have realized that their "jobs are more complex than ever before. They must respond to the needs of a diverse and changing student population, a rapidly changing technology in the workplace, and demands for excellence from all segments of society" (Fullan, 1993, p. 5).

Similarly, research has shown that promising changes won't occur in teachers' practice unless they experience high quality professional development (PD) (Rhoton and Stile, 2002). Accordingly, educators, policy makers and researchers have urged the need to transform teacher professional development and increasing the quality of PD interventions has become a "central component in nearly every modern proposal for improving education" (Guskey, 2002, p. 381). In particular, appreciation of teachers' engagement in their life long learning and attributing greater importance in creating opportunities for their continual growth along with more educational supports and resources (Darling-Hammond, 1990, 1996; Tsafos and Katsarou, 2000) has become a paradigm shift in educational settings and teacher improvement plans have been redefined from an isolated culture to a collaborative culture that appreciates and supports the improvement of individual teachers as well as aiming at promoting the whole school improvement (Lieberman, 1995).

To be more specific, in line with new demands in educational arena, the perspective taken to look at professional development has tremendously geared from passive participation in workshops to an active, continuous and constructive process that is problem oriented, grounded in social situation, and takes place throughout teachers' lives (Ten Dam and Blom, 2006 as cited in Geijsel, Sleegers, Stoel, and Kruger (2009). In this lifelong learning process which is heavily influenced by the "situated cognitive theories" on learning and "adult learning theories", teachers take responsibility for their professional improvement and equip themselves with the necessary knowledge to take part critically in educational setting. In so doing, teachers not only individually grow but also stimulate the development of the whole school (Geijsel, et al., 2009). 
If we are to truly transform teaching and if we really attempt to bring about quality in schools, we should direct all our energies toward creating change in professional development interventions. This will not occur unless we take into account the factors and conditions influencing teacher development and growth. Yet, as stated by many famous scholars in the field of teacher education "Factors that influence teacher learning and development have not been widely studied" (Darling-Hammond and McLaughlin, 1995; Eraut, 1994; Lieberman, 1995). Acknowledging this limitation, this study aims at contributing to the literature of teacher professional development by examining the individual and organizational factors motivating or inhibiting teacher professional development. The research questions of this study are the following:

1. What are the individual factors conducive to teacher professional development?

2. What are the contextual factors conducive to teacher professional development?

\section{Method}

\subsection{Sampling}

Purposeful sampling was adopted in this study. As declared by Patton (2002) purposeful samples are information rich individuals that can address the issues related to the research. Utmost attention was paid to choosing information rich informants. In addition, in some cases, snowball sampling followed purposeful sampling as suggested by Patton (2002). The interview process starts by asking "well suited people 'who know about x' and by asking a number of people; the snowball gets bigger as you accumulate information rich cases" (Patton, 2002, p. 237).

Seidler (1974) comprehensively examined different sample sizes of interviewees chosen purposefully and declared that at least five informants are needed to achieve reliable data. Fifteen teachers working in different English institutes from four regions of ministry of education were chosen to take part in this qualitative study. The number of teachers participating in the interview was determined based on data saturation point as a time in which no new data or very little new data emerges from the upcoming interviews (Creswell and Plano Clark, 2006).

\subsection{Data Collection Procedure}

In line with our objectives, interviewees were asked to answer a limited number of open-ended questions in a series of semi-structured interviews. A semi-structured format helps the interviewer take a flexible stance as different interviewees answer the questions differently (Creswell and Plano Clark, 2006). Besides, semi-structured questions foster guiding the interview and keep participants focused to ensure that the needed data is provided. This stands in sharp contrast to an open interview in which participants can freely talk about a range of topics (Flick, 2005).

Each interview lasted about approximately 45 to 60 minutes. The interviews helped the researcher look for emerging themes which could further be explored through the quantitative approach. The major aim of this qualitative study was recognizing the personal and contextual factors that motivated or de-motivated teachers to engage in continuous improvement activities. In addition, at this stage, a comprehensive literature review was performed to complement and testify the qualitative findings.

\subsection{Data Analysis}

Immediately after the first few interviews, they were transcribed and analyzed. Content analysis methodology was adopted to code the data. Content analysis is defined as "a research method for the subjective interpretation of the content of text data through the systematic classification process of coding and identifying themes or patterns." (Hsieh and Shannon, 2005, p.1278). It is a "qualitative data reduction and sense-making effort that takes a volume of qualitative material and attempts to identify core consistencies and meanings" (Patton, 2002, p. 453).

The interview transcripts were read carefully and annotated. During this process, important concepts were labeled as new themes emerged. Notations were made in the margins of the text to indicate a code. The coding unit was based on Schamber' s (2000) suggestion who stated that coding unit can be " a word or group of words that could be coded under one criterion or category"(p. 739). It is worth mentioning that the researcher checked the coding continuously and as upcoming data were collected, new codes and themes were added to the coding manual.

Two main criteria were used to determine the relevance of data to this study: their relevance to research questions and the relationship between interviewees' ideas and existing theories. Naming the codes was guided by the review of literature.

In order to check for the qualitative data credibility, triangulation was employed using various sources such as a comprehensive review of literature, and the use of applied research results to generate potential predictors of teacher professional development. Doubts regarding specific categories were discussed with experienced experts in the relevant area. Besides, peer debriefing was applied. Peer debriefing was performed in the interview process as the researcher paraphrased the interviewees' idea to refine and interpret. It was used to "confirm interpretations and coding decisions including the development of categories" (Foster, 2004, p.231).

\section{Findings}

The first research question addressed individual factors affecting teacher development. Three themes emerged from teachers' interview: 


\subsection{Learning Goal Orientation}

The first theme concerned teacher learning goal orientation. Teachers stated that pursuing a goal, especially a learning goal was very much conducive to their development. They said that individuals who always aspire to learn and develop their competence are professionally more developed than those who don't follow any learning goals. The following statements from the interview transcripts are provided to articulate the findings:

Well, I believe that pursuing goals is the most important determinant factor to improve. Some people prefer their peaceful life. They don't want to get out of their relaxing situation. But for me, it is different. When I am engaged in doing something, I always think about my future goals. I don't want to become stagnant. I remember, I first started with teaching children but this didn't satisfy me. I have always wanted to teach at the university level. This is the aim I pursue.

Interestingly, the important role of learning goal orientation was especially evident in teachers who were more actively involved in their development. In this regard, a teacher who claimed she was very much engaged in self directed learning activities said:

I have always been keen to learn new things. No one is perfect. I always hope to improve my teaching skills. I enjoy challenging myself with different activities such as planning new creative games, new pair activities, and etc. I don't care about what others say about my salary. I love to learn new techniques and teaching skills. I always embrace change.

\subsection{Teacher Self Efficacy}

The second theme was teacher self efficacy. Some teachers stated that teachers' beliefs in their abilities and their judgments about their teaching greatly motivated them to professionally grow. The following interview excerpt summarizes this theme:

Based on the observers and students' feedback, I think I have been a successful teacher. This gives me extra motivation to improve. I can make my students understood and I can communicate very well with them... I think I have been made for the teaching job.

\subsection{Professional commitment}

A much frequently mentioned theme was the psychological bond between teachers and their profession. It was assumed as a factor that overrode the negative effect of contextual factors to the extent that some teachers dissatisfied with the climate of the institute or the financial issues said that they were eager to develop their competence because they loved teaching. The following comment is provided as support for these findings:

I believe that the most important factor in teacher development is emotional attachment to the teaching job. This gives teachers the motivation to do whatever they can to improve their teaching skills. If you don't like teaching, you won't like your students either and you won't do anything to improve your knowledge.

The second qualitative research question targeted the contextual factors affecting teacher development. Two themes emerged as the contextual drivers of professional development namely organizational climate and learning organization culture.

\subsection{Organizational Climate}

Organizational climate addressed how teachers perceived and experienced the immediate teaching environment, their colleagues, and managers' attitudes toward them. One frequently mentioned dimension of climate was collegial relationships among staffs. Teachers indicated that colleagues and educational staffs' relationships and attitudes extremely impacted their professional development. This was especially evident in teachers' comment about managers' and observers' attitude and behavior toward them. Most teachers enjoyed the warm atmosphere in the institute and felt positive about their colleagues and they said that this is one of the most important factors which makes them feel driven to work and consequently to improve in their profession. One teacher stated:

I have taught in this institute for 10 years. What keeps me attached to this job is the close relationship among me, my colleagues and students. When we come to the office for the break, we share our feelings, concerns and even worries. When I share the dilemmas I have faced in the class with my colleagues, they provide me with good suggestions... We are not just colleagues. We sometimes hold parties or even go out together.

Another dimension of this theme referenced by the participants was teacher collaboration. Some teachers stated that their individualistic style of development was promoted by the institute policies which hindered their improvement. The following statements verify this:

There is no team spirit. Everyone works individually. We don't share our experiences. We sometimes talk to a friend or a colleague about instructional issues but I think it doesn't suffice. Unfortunately, other colleagues look down on us when we ask them questions while we should collaborate, share ideas, pose questions and get feedback. Each of us has some kind of potentials which others can take advantage of.

Another teacher approving of collaborative activities emphasized that the basics and the policies behind collaboration should be highlighted before encouraging teachers to collaborate:

Group work affects teacher development but unfortunately in Iran collaboration has not been defined well. Here, even in group activities, everyone seeks his own personal advantage and tries to undermine or pick up on his colleague to 
highlight his own strengths and superiority. So everyone prefers individualistic activities and collaboration in its present form has a negative impact on teachers.

All in all, most teachers stated that they wished there would be more collaboration among teachers which would help them professionally develop.

Fairness was another recurring dimension of organizational climate. Teachers thought that educational staffs' subjectivity and favoritism despaired them and hindered their development. Some stated that managers play favorites and that teachers don't have equal opportunities for improvement. They believed that these unfair privileges extremely demotivated them. In particular, some teachers referenced observers' subjectivity as a barrier to improvement and they mentioned that observers should have a supportive relationship grounded in objectivity and fairness so that teachers would achieve most of this partnership activity. In this regard, one teacher said:

Observers pick on us about unimportant things. I'm sure, I have had so many positive points in my teaching performance but observers just focus on unimportant issues. To be honest, their behavior really demotivates and embarrasses me. Instead of providing us with informational objective feedback, they give us judgmental opinions. It is also not accompanied by how our performance should improve.

The same theme was addressed by another teacher:

I feel uncomfortable with most observers. Their feedback contains no positive points or comments and there is no language of support. They despise us. Some even have humiliating behavior. They should provide us with objective feedback and highlight our positive points. I remember an experience concerning group observation. One observer told me, I observe teachers' classes. I will teach them and they will learn.

Few teachers, however, felt that observers were a part of them and they were quite satisfied with the fair and constructive feedback they were provided with. This feeling was specially reinforced with the peer debriefing they had with the observers the day after being observed during which they talked logically about positive points and the points which needed to be improved.

\subsection{Learning Organization Culture}

The final theme extracted from the interview transcripts was learning organizational culture. One dimension of this theme as reported by teachers was ongoing learning. The following magnets show how critical it is for the educational staff of the institute to inspire continuous learning in teachers:

Because of low salary some teachers have quit this institute. But after a while, they were all back at their old jobs... I think the most important motivator is that in this institute we have great chances of learning new skills, strategies and ideas. Every one has to be continuously learning. Although it creates great pressure on new teachers, the atmosphere is such that after some times even new teachers are encouraged to actively involve in continuous learning. I have been teaching at this institute for five years but I try to get prepared as a novice teacher does. My desk is full of books, dictionaries, and CDs. I always check various internet sites to get more information. I buy new books of great teaching scholars such as Douglas Brown and Jeremy Harmer.

This teacher continued:

If I teach at some other institutes, I am sure I will earn much more money. But I can't quit teaching here because in this institute teachers have to take part in various workshops and training sessions. Every day I learn something new. We have to pay for the teacher training courses, but they are really worth it. These classes are obligatory, but even if they were optional, I'm sure I definitely wouldn't miss them.

Teachers also stated that regular workshops does not necessarily guarantee continuous learning unless they are based on teachers' immediate needs; this spurs an urgent call that the educational staff should initially inquire into teachers' basic needs for improvement.

Another factor which some believed would contribute to teacher development was the important role of managers and educational staff who not only encourage teachers to learn but also are personally involved in the act of learning themselves. In support of this theme one teacher stated:

Fortunately, we have different workshops. Not only are the workshops held for ordinary teachers but also educational staff and observers themselves participate in these classes. It's good to see the educational staff with us learning in these classes. We think we have equal opportunities to learn...Interestingly, some of the educational staff go to Tehran on a regular basis and update their knowledge to learn new ides which will be transferred to us.

But few other teachers stated that ongoing efforts to ensure continuous learning were not fruitful because these interventions were run by ordinary teachers who were a bit more experienced or knowledgeable than them and this, they claimed would greatly demotivate them.

Teacher empowerment was another recurring theme addressed by teachers. Two sources of empowerment were shared decision making and autonomy. Most teachers stated that they would expect the educational staff to value their constructive opinion and to encourage teachers to share their novel ideas and to influence the educational policies and have more voice in instructional decisions and as a consequence, they strongly opposed to managers' dictating their ideas to them and forcing them to follow the rules.

The following statement testifies this: 
Unfortunately, students' needs are not much considered. We are closer to the students and we know their needs much better than managers. I'm afraid at this institute there are some strict rules which we should follow. This puts great pressure on teachers... um, kind of job stress. I mean we can't be much creative in our teaching. I think teachers should have somehow more freedom in their educational methods and strategies. In that case, they will have more motivation to grow as they assume the full responsibility for student' achievements.

Unfortunately, the most important obstacle to teacher empowerment was that some teachers felt that they were not valued or recognized for their sincere attempts while they expected to be heard for their genuine praise and encouragement. This was clearly voiced by one teacher's comment:

"We have an authoritarian manager. He doesn't value our insightful suggestions. We like to be valued..."

Most teachers thought the staff just wanted them to work and improve for the financial benefit of the institutes stakeholders. Although most teachers had negative perceptions about being appreciated or valued by managers, few felt valued and recognized. In particular, they stated that managers' kind behavior, their understanding of teachers' constructive suggestions and their personal concerns, in addition to the educational staff's talking respectfully to teachers in case they were criticized by students as factors which proved that they were of value and this substantially lifted their spirits and motivated them to advance their careers.

In addition, many teachers mentioned financial reward in form of salary raise as a factor which motivated them to professionally advance in their careers. These teachers stated that they were dissatisfied by the mere annual salary raise and further demanded to be rewarded on the basis of their improvement, too.

\section{Discussion and conclusion}

\subsection{Learning Goal Orientation}

A major finding of this study, utilizing the qualitative methodology was that language goal orientation enhances teacher professional development. This is consistent with the results of previous studies including Brett and VandeWalle (1999) and Park (2011) who found the critical role of learning goal orientation in enhancing teacher development. Learning goal orientation has been related to engagement in self regulated learning activities including the employment of cognitive strategies, monitoring, asking for feedback, help seeking, and planning ( Meece, Blaumenfield, and Hoyle, 1988). Research shows that learning goal orientation as compared to performance goal orientation does not only affect teacher learning, but also it influences the transfer of learned knowledge (Kraiger, Ford, Salas, 1993).

In a similar vein, researchers have documented that individuals high in learning goal orientation are much more eager to acquire new knowledge and skills through performing challenging tasks (Hirst,Van Knippenberg, and Zhou, 2009). These individuals are continuously involved in creating knowledge, improving skills and finding solutions to problems (Porter, 2005) which accounts for why they are professionally more developed.

\subsection{Teacher Self Efficacy}

Teachers in the interview mentioned that one of the psychological mechanisms thriving their development was self efficacy especially the teaching self efficacy. They stated that self efficacious teachers were more confident about their ability and were more likely to advance their professional career. This supports the important role of self efficacy as the core of Bandura's social cognitive theory in nurturing teacher development. "Self-efficacy beliefs are critical ingredients in human functioning and they provide the foundation for human motivation, well-being, and personal accomplishment" (Pajares, 2002, n.p).

Teachers high in self efficacy are more creative in their job, and intensify their attempts when they fall behind their scheduled goals and persist longer in their development (Guskey and Passaro, 1994). Research has also demonstrated that highly efficacious teachers attempt to explore different methods of instructions, look for the best teaching methods and strategies and experiment with various instructional methods (Allinder, 1994). Several other studies including Daal, Donche, and De Maeyer (2013) and Eden and Kinnar (1991) have also indicated the positive influence of self efficacy on individual's development.

\subsection{Professional Commitment}

Additionally, data gathered through the in-depth interviews indicated that one major psychological mechanism boosting teacher development was teachers' interest in their job. The findings support the fact that professionally committed individuals form a stronger bond to their profession and are more open to learning opportunities. This finding is also echoed by many other researchers ( Day and Gu, 2007; and Lam and Pang, 2003).

\subsection{Organizational Climate}

Teachers also acknowledged that the climate of institute did tremendously impact their professional growth. They particularly mentioned collegial relationship as an extremely conducive element to their development. Collegiality promotes teacher development because it acts as a great source of stimulation for teachers (Lieberman and Miller, 1984; Rosenholtz, 1989). On top of all, teachers stated that managers play a critical role in building and promoting a collegial workplace. The interviews showed that even those managers who encouraged continuous learning didn't succeed in promoting teacher development unless they fostered trust and respect among the staff. It was demonstrated that undermining trust poisoned work environment and militated against teacher and school; a finding consistent with Clement and Vandenberghe (2000). 
Collaboration and healthy exchange of idea was another important contributor to building teaching expertise. Collaboration is a vital element for teacher development (Rogers and Babinski, 2002). "In collaborative working environments, teachers have the potential to create the collective capacity for initiating and sustaining ongoing improvement in their professional practice, so each student they serve can receive the highest quality of education possible" (Pugach and Johnson, 2002, p. 6). Teachers in a collegial collaborative environment build professional interaction through sharing ideas, looking for feedback and helping each other in instructional practices. These sorts of interactions, in turn, promote more successful teacher development. This confirms the findings of empirical studies by Louis, Kruse, and Marks (1996) who provided evidence for the paramount role of creating extensive opportunities for collaboration to enhance teacher continuous development.

Subjectivity and favoritism was also enumerated by many teachers in the interview as a potential obstruction to teacher development. They claimed that subjective treatment of teachers had adverse effects on their motivation to develop. "When teachers perceive the principal as being fair, respectful, and equitable, they may be more apt to exhibit desirable work behaviors that exceed minimal contractual expectations and benefit individuals and the school ( Burns, 2013, p.45). This agrees with the work of Oti (2012) who maintained that fairness as an organizational climate dimension influenced individual's career growth. These findings show that organizational climate has a critical role in enabling teachers to maximize their competence which mirror the work of Bryk, Camburn, and Louis (1999) and Foley and Clifton (1990) .

\subsection{Learning Organization Culture}

Teachers, in the interview, identified learning organization culture in three ways: Ongoing learners, lead learner and empowerment. It was primarily shown that teacher development hinges on the continuous learning culture. The interviews highlighted the fact that the educational staff and managers' emphasis on continuous learning yielded higher teacher development. These administrators were well cognizant of the fact that in order to thrive and survive in today's turbulent world, teachers should be mobilized and engaged in the active process of learning and growth.

Second, some teachers mentioned that educational staff and leaders' eagerness to learn and keep updated was instrumental to their learning and it acted as a catalyst for their motivation. Teachers were more enthusiastic to learn if they worked in the institutes in which the educational staff themselves aspired for their lifelong learning. This as they stated boosted their motivation and doubled their energy to learn. As Kouzes and Posner (1995) claimed leadership is grounded in change. In fact, learning has been considered as "a foundational element in effective leadership" (p. 323). Effective leaders are engaged in a continuous process of learning. These leaders "see all experiences as learning experiences" (Kouzes and Posner, 1995).

Empowerment was another frequently mentioned theme which as teachers stated had a great impact on their desire to continuously learn and improve. "People are more willing to develop and perform when learning builds on their strengths" (McNabb, 2007, p.80). According to Burdett (1991) empowerment is an essential feature for an organization to increase its learning capacity.

Most teachers in the interview said that they would like to be appreciated and valued for their attempts. This demonstrates that acknowledging teachers' professional status and appreciating them is an essential element to teacher success (Evans, 1998). Besides, interviewees stated that they claimed their right to voice their opinion and to be involved in decision making related to the institute policies and they stated that this would contribute much to their development. As viewed by Cochran-Smith (1991) "teachers are decision makers and collaborators who must reclaim their roles in the shaping of practice by taking a stand as both educators and activists" (p. 280).

In addition, another source of empowerment as claimed by teachers was autonomy. The less the interviewees felt controlled by managers, the more they were affected by inner drives to professionally grow. "Genuinely successful teachers have always been autonomous in the sense of having a strong sense of personal responsibility for their teaching, exercising via continuous reflection and analysis the highest degree of affective and cognitive control of the teaching process, and exploring the freedom that this confers" (Little, 1995, p.179).

\section{Implications of the Research Findings}

The findings of this study has a number of implications for teacher professional development, learning goal orientation, teacher self efficacy, organizational climate, and learning organization culture. As far as theory is concerned, the results of this study provide additional information to support teacher professional development in the field of teacher education. This study indicated that professional development as a complex process is influenced by the simultaneous interaction of various psychological and contextual factors. Therefore, educational managers should leverage all their potentials to promote teacher development by simultaneously focusing on psychological and contextual drivers. Specifically, there were five personal and contextual factors that interactionally contributed to teacher growth.

\subsection{LGO Implications}

Teachers should be provided with enough opportunities which foster team work and collaboration among educators focusing on learning for the sake of development and growth as opposed to a competitive environment as a hostile force which would be counter productive to teacher motivational development. Teachers in this environment should be encouraged to take risk and engage in a continuous process of trial and error. 


\subsection{Teacher Self Efficacy Implications}

Concerning the emphasis of social cognitive theory on the critical role of human agency as the cornerstone of teacher self efficacy (Bandura, 1997), stakeholders are invited to focus their attention on designing various collaborative activities ( Newmann, Rutter, and Smith, 1989) which engage teachers in the critical examination of their own classrooms and implementation of new interventions. Teachers can form professional learning communities grounded in collaborative activities, shared dialogue and peer support. These would drive teachers' professional communication and would prove their confidence in their ability.

In addition to addressing the relevant psychological mechanism affecting teacher development, educational institutes should fulfill some prerequisite conditions in order to foster teachers' sustained learning. Many scholars maintain that in order to stimulate teacher learning, certain learning infrastructure is needed (Darling-Hammond, 1998 ) in educational centers. Therefore, it seems pertinent to highly address contextual issues such as organizational climate and learning organization culture.

\subsection{Organizational Climate Implications}

The study indicated that a healthier climate would lead to a higher professional development. Organizational climate is effective when it includes encouraging collaboration and information sharing; showing appreciation for creative and novel oriented approaches to teaching, provides better facilities, nurtures better relationship among teachers, students and administrators, and finally provides substantial administrative teacher support.

\subsection{Learning Organization Climate Implications}

The study showed associations between teachers' perception of their learning organization culture and their professional growth. When teachers in the past were awarded educational certificates, they ceased to further their development. However, to keep pace with new information explosion, modern educational system considers learning as a lifelong sustained process. In this regard, policy makers, educators and school managers play a vital role in establishing and maintaining a learning environment through which they can engineer diverse opportunities for teachers' continuous learning.

Teachers should be given extensive opportunities to experiment with new experiences on a continuous basis in their work place environment. Accordingly, managers should provide a wealth of administrative support and rewards for teachers to engage in continuous learning. However, administrative staff should initially serve as an example of someone highly interested in pursuing learning; someone who is emulated by other teachers.

These managers should cultivate a spirit of learning by first articulating a clear vision which as a catalyst makes clear their long term direction and guides every aspect of teachers' movements. Additionally, educational staff needs to foster an environment oriented in mutual trust and encouragement which promotes what $\mathrm{Wu}$ and Chen $(2012$, p. 92) call "top-to-bottom equal spirit of cooperation" removing structural hierarchies with order from top to bottom emphasizing equality. Besides, as knowledge is constructed socially, teachers in this nurturing environment should be encouraged to openly share and discuss issues with their colleagues. Through stimulating dialogue, individuals give a way to individualistic trends to teaching and move toward sharing meaning; uncovering the unknowns and unlocking their potentials.

Finally, teacher empowerment is another issue that should be addressed when planning to improve teacher development. To do so, school managers should acknowledge teachers' professional status and reward them accordingly. Kouzes and Posner's (1995) state that "Encouragement through the celebration of successes, big and small, motivates people to continue to take risks and remain committed to the organization's goals. Such genuine care provides people with the spirit to overcome insurmountable obstacles" (p. 634).

\section{References}

Allinder, R. M. (1994). The relationships between efficacy and the instructional practices of teachers and consultants. Teacher Education and Special Education, 17, 86-95.

Bandura, A. (1997). Self-Efficacy: The exercise of control. New York: W.H. Freeman Company.

Brett, J. F., \& VandeWalle, D. (1999). Goal orientation and goal content as predictors of performance in a training program. Journal of Applied Psychology, 84 (6), 863-873.

Bryk, A., Camburn, E. \& Louis, K.S. (1999). Professional community in Chicago elementary schools: Facilitating factors and organizational consequences. Educational Administration Quarterly, 35, 751-781.

Burdett, J.O. (1991). What is Empowerment Anyway? Journal of European Industrial Training, 15 (6), 23-30.

Burns, T. (2013). Teachers' perceptions of fairness and equity are essential to a successful principalship. NASSP Principal Leadership, 13 (7), 42-45.

Clement, M. \& Vandenberghe, R. (2000). Teachers' professional development: a solitary or collegial (ad)venture? Teaching and Teacher Education, 16, 81-101.

Cochran-Smith, M. (1991). Learning to teach against the grain. Harvard Educational Review, 51 (3), 279-310. 
Creswell, J.W., \& Plano Clark, V. (2006). Designing and conducting mixed methods research. Thousand Oaks, CA: Sage.

Creswell, J. W., Plano Clark, V. L., Gutmann, M. L., \& Hanson, W. E. (2003). Advanced mixed methods research designs. In A. Tashakkori \& C. Teddlie (Eds.), Handbook of mixed methods in social and behavioral research (pp. 209-240). Thousand Oaks, CA: Sage.

Daal , T. V. , Donche, V. \& De Maeyer, S. (2013). The Impact of Personality, Goal Orientation and Self-Efficacy on Participation of High School Teachers in Learning Activities in the Workplace. Vocations and Learning, 1-20.

Darling-Hammond, L. (1990). Instructional policy into practice: The power of bottom over the top. Educational Evaluation and Policy Analysis, 12, 233-241.

Darling-Hammond, L. (1996). The quiet revolution: Rethinking teacher development. Educational Leadership, 53 (6), 4-10.

Darling-Hammond, L. (1998). Teacher learning that supports student learning. Educational Leadership, 55 (5), 6-11.

Darling-Hammond L. \& McLaughlin M.W. (1995). Policies that support professional development in an era of reform. Phi Delta Kappan, 76 (8), 597-604.

Day, C. \& Gu, Q. (2007). Variations in the Conditions for Teachers' Professional Learning and Development: Sustaining Commitment and Effectiveness over a Career. Oxford Review of Education, 33 (4), 423-443.

Eden, D., \& Kinnar, J. (1991). Modeling Galatea: Boosting self-efficacy to increase volunteering. Journal of Applied Psychology, 76 (6), 773-780.

Eraut, M. (1994). Developing professional knowledge and competence. London: Falmer Press.

Evans, L. (1998). Teacher morale, job satisfaction and motivation. London: Paul Chapman Publishing Limited.

Flick, U. (2005). An introduction to qualitative research. Thousand Oaks, CA: Sage Publications.

Foley, J. R. \& Clifton, R. A. .(1990). Locus of control, organizational climate, and participation in staff development: A study of college instructors. The Canadian Journal of Higher Education, XX-2 , 45-59.

Foster, A. (2004). A nonlinear model of information-seeking behavior. Journal of the American Society for Information Science \& Technology, 55 (3), 228-237.

Fullan, M. (1993). Change forces: probing the depths of educational reform. London, New York, Philadelphia: The Falmer Press.

Garet, M. S., Porter, A. C., Desimone, L., Birman, B. F., \& Yoon, K. S. (2001). What makes professional development effective? Results from a national sample of teachers. American Educational Research Journal, 38 (4), 915-945.

Geijsel, F., Sleegers, P., Stoel, R. \& Kruger, M. (2009). The Effect of Teacher Psychological, School Organizational and Leadership Factors on Teachers' Professional Learning in Dutch Schools. The Elementary School Journal, 109 (4), 406-427.

Guskey, T. (2002). Does it make a difference: Evaluating professional development. Educational Leadership, 59, 4551.

Guskey, T.R. \& Passaro, P.D. (1994). Teacher efficacy: A study of construct dimensions. American Educational Research Journal, 31, 627-643.

Hirst, G., van Knippenberg, D. \& Zhou, J. (2009). A cross-level perspective on employee creativity: Goal orientation, team learning behavior, and individual creativity. Academy of Management Journal, 52, 2, 280-293.

Hsieh, H.-F., \& Shannon, S.E. (2005). Three approaches to qualitative content analysis. Qualitative Health Research, $15(9), 1277-1288$.

Kouzes, J. M., \& Posner, B. Z. (1995). The leadership challenge: how to keep getting extraordinary things done in organizations. California: Jossey-Bass.

Kraiger, K., Ford, J. K. \& Salas, E. ( 1993). Application of cognitive, skill-based, and affective theories of learning outcomes to new methods of training evaluation [Monograph]. Journal of Applied Psychology, 78, 311-328.

Lam, Y.L.J. \& Pang, S.K.N. (2003). The relative effects of environmental, internal and contextual factors on organizational learning: the case of Hong Kong schools under reforms. The Learning Organisation, 10 (2), 83-97.

Lieberman, A. (1995). Practices that support teacher development: Transforming conceptions of professional learning. Phi Delta Kappan, 76 (8), 591-596.

Lieberman, A., \& Miller, L. (1984). Teachers, their world and their work: Implications for school improvement. Alexandria,VA: Association for Supervision and Curriculum Development.

Little, D. (1995). Learning as dialogue: The dependence of learner autonomy on teacher autonomy. System, 23 (2), 175182.

Louis, K., Kruse, S., \& Marks, H. M. (1996). School wide professional community. In F. M. Newmann (Ed.), Authentic achievement: Restructuring schools for intellectual quality (pp. 179-204). San Francisco: Jossey-Bass. 
McNabb, D. E. (2007). Knowledge management in the public sector: A blueprint for innovation in government. New York: M. E. Sharpe, Inc.

Meece, J. L., Blumenfeld, P.C., \& Hoyle, R.H. (1988). Students' goal orientations and cognitive engagement in classroom activities. Journal of Educational Psychology, 80, 514-523.

Newmann, F.M., Rutter, R.A., \& Smith, M.S. (1989). Organizational factors that affect school sense of efficacy, community and expectations. Sociology of Education, 62, 221-238.

Oti, A. O. (2012). Organizational climate predictors of female academics' career growth and leadership position. Retrieved from https:/www.google.com/url?sa=t\&rct=j\&q=\&esrc=s\&source=web\&cd=1\&cad=rja\&ved

Pajeres, F. (2002 ). Overview of social cognitive theory and self efficacy. Retrieved from http://www.uky.edu/ eushe2/Pajares/eff.html

Park, S. ( 2011). The impact of organizational learning culture, goal orientation, managerial effectiveness, and psychological empowerment on employees' workplace learning, University of Minnesota, ProQuest, UMI Dissertations (3465136).

Patton, M.Q. (2002). Qualitative research and evaluation methods. Thousand Oaks, CA: Sage.

Porter, Ch, O. L ( 2005). Goal orientation: Effects on backing up Behavior, performance, efficacy, and commitment in Teams. Journal of Applied Psychology, 90 (4), 811-818.

Pugach, M. C, \& Johnson, L. J. (2002). Unlocking expertise among classroom teachers through structured dialogue: Extending research on peer collaboration. Exceptional Children, 62, 101-110.

Rhoton, J., \& Stiles, K. E. (2002) Exploring the professional development design process: Bringing an abstract framework into practice. Science Educator, 11( 1), 1-8.

Rogers, D., \& Babinski, L. (2002). From isolation toconversation: Supporting new teachers' development. Al- bany, NY: State University of New York Press.

Rosenholtz, S. J. (1989). Workplace conditions that affect teacher quality and commitment: Implications for teacher induction programs. Elementary School Journal, 89, 421-439.

Schamber, L. (2000). Time-line interviews and inductive content analysis: Their effectiveness for exploring cognitive behaviors. Journal of the American Society for Information Science, 51( 8) 734-744.

Seidler, J. (1974). On using informants: a technique for collecting quantitative data and controlling measurement error in organization analysis. American Sociological Review 39, 816-831.

Tsafos, V., \& Katsarou, E. (2000). Action research in the professional development of teachers. Contemporary Education, 114, 67-74

Wu, M \& Chen, Ch. (2012). Obstacles of organizational learning and self-transcendence: theoretical research based on Chinese family business. Asian Social Science, 8, 13, 89-94. 